\title{
Trends of Thyroid Cancer Mortality Rates in Ecuador
}

\author{
Enrique López Gavilanez ${ }^{1,2^{*}}$, Kempis Guerrero Franco ${ }^{2,3}$, Angel Segale Bajaña ${ }^{2,3}$, Noemi Bautista Litardo ${ }^{2}$, \\ Manuel Navarro Chávez ${ }^{2}$, Mario Hernández Bonilla ${ }^{1,2}$, Narcisa Solórzano Romero ${ }^{2}$, Marcos loor Goya ${ }^{2}$ \\ ${ }^{1}$ Servicio de Endocrinología, Hospital Docente de la Policía Nacional Guayaquil № 2, Guayaquil, Ecuador \\ ${ }^{2}$ AECE Research Group, from the Association of Clinical Endocrinologists of Ecuador, Guayaquil, Ecuador \\ ${ }^{3}$ Servicio de Medicina Interna. Hospital Docente de la Policía Nacional Guayaquil № 2, Guayaquil, Ecuador
}

Received: August 13,2018; Accepted: August 22,2018; Published: August 27,2018

*Corresponding author: Enrique Lopez Gavilanez, Hospital de la Policía Nacional Guayaquil No.2. Avenida de las Américas S/Ny E Noboa. Zip code: EC090150. Guayaquil, Ecuador; E-mail: enrique_lopezg57@hotmail.com

\section{Abstract}

Objective: To analyze thyroid cancer (TC) mortality rates from 1990 to 2016 in Ecuadorian men and women and compare their trends with Latin American and international trends.

Design: A population-based temporal-trend study using the database of the Ecuadorian National Death Registry.

Methods: Crude and age-adjusted mortality rates were calculated, and age-related mortality rates were standardized with the world population (WHO). Trends in age-standardized mortality rates were estimated by jointpoint regression analysis. The trends were expressed as annual percentage change (APC) and average annual percentage change (AAPC)

Results: In total, TC caused 2,107 deaths $(1,475$ women and 632 men) in the selected period. The mortality in men showed a statistically non-significant decrease. The estimated APC was $-0.4 \%(\mathrm{P}=0.70)$, and the AAPC was $-0.4 \%(\mathrm{P}=0.70)$ without any identified jointpoint. In women, the mortality decreased significantly between 1990 and 1998, with the estimated APC being $-6.6 \%$ ( $\mathrm{P}<$ 0.05). However, it increased significantly from 1998 to 2016, with the estimated APC of 5.4\% ( $<$ < 0.05), and a jointpoint was identified; the AAPC was $1.4(\mathrm{P}=0.30)$.

Conclusions: While TC mortality in Ecuadorian men showed a decrease, that in Ecuadorian women showed an initial decrease and a final increase. Our findings can be contrasted with the global data, which show decreases in TC mortality in both sexes.

Keywords: Thyroid Cancer; Epidemiology; Trends; Mortality; Ecuador

\section{Introduction}

Although thyroid cancer (TC) is a relatively rare type of cancer, it is the most common cancer of the endocrine system, representing $96 \%$ of newly diagnosed endocrine cancers and $66.8 \%$ of related deaths [1]. In Ecuador, TC ranks fourth among the top 10 most common types of cancer in women [2].

The incidence of TC may be up to 10 times higher in developing countries than that in developed countries, and TC mortality shows unchanging or declining rates in both types of countries [3-6]. However, recently an increase in TC mortality has been observed in several countries, including the United States [7].
In 2012, the global TC mortality rates were approximately 0.6 per 100,000 women and 0.3 per 100,000 men [7]. In Europe, TC mortality has declined in many countries; however, the mortality rates vary by country, and very few studies tend to focus only on mortality [8]. In addition, mortality from TC in Europe varies greatly by sex, with higher rates observed among women $(0.4$ per 100,000 women vs. 0.3 per 100,000 men) [8].

Although TC mortality is low and has been declining worldwide, mortality-based population studies are rare. In particular, temporal trends in TC mortality in Ecuador have not been previously reported. Therefore, the present study aimed to analyze TC mortality rates in the Ecuadorian population from 1990 to 2016 and attempted to evaluate how they compared with those in Latin America and the rest of the world.

\section{Subjects and Methods}

A temporal-trend study based on the Ecuadorian population was conducted from 1990 to 2016 using information in the database of the Ecuadorian National Death Registry [9], along with the population data from 1990 to 2016 published by the Centro Latinoamericano y Caribeño de Demografía [10].

The following codes International Classification of Diseases (ICD) for TC diagnosis were included in the analysis: ICD 9, from 1990 to 1996, code 193 (malignant neoplasms of the thyroid gland) and ICD 10, from 1997 to 2016, code C73 (malignant thyroid neoplasia).

The variables included the recorded year of death, total population per year, number of deaths, sex, age, state or province of residency, and code of the basic cause of death. Specific mortality rates were calculated considering the age and sex and were expressed in deaths per 100,000 individuals per year. The age groups included five-year ranges: $20-24,25-29,30-34,35-$ 39 , 40-44, 45-49, 50-54, 55-59, 60-64, 65-69, 70-74, 75-79, $80-84$, and $\geq 85$ years.

To assess temporal changes in TC mortality, the mortality rates were estimated yearly from 1990 to 2016 . Age-related mortality rates were standardized by the direct method using the world population (WHO) as the standard. jointpoint regression analysis 
was used to estimate trends in age-standardized mortality rates for both the sexes. Mortality rates were predicted for the years 2030, 2040, and 2050 using the Statistical Package for Social Sciences (IBM® SPSS $\AA$, version 23.0, Armonk, NY, USA). The trends were expressed as annual percentage of change (APC) and average annual percentage of change (AAPC).

The trends in the mortality rates were modeled through regression analysis of inflection points (jointpoint). A final best-fit model was selected with the estimated APC based on a trend within each segment. The trends are presented with their corresponding 95\% confidence interval (CI). P $<0.05$ was considered statistically significant.

AAPC estimation involves using the underlying jointpoint model to calculate a summarized measure over a pre-specified fixed interval. This allows us to use a single number to describe the average of APCs over several years. It is valid even if the jointpoint model indicates that there were changes in trends during those years. It is computed as a weighted average of the APCs of the jointpoint model with weights equal to the length of the APC interval.
The jointpoint Regression ${ }^{\circledR}$ program version 4.5.0.1 (National Cancer Institute) [11] was used to process the data. Projects involving survey/research and analysis of bibliographic databases within the public domain (e.g., www.ecuadorencifras. gob.ec [9]) do not require ethics approval.

\section{Results}

During the analyzed period, there were 2,107 deaths due to TC (1,475 women and 632 men). The absolute number of female deaths due to TC increased from 37 in 1990 to 101 in 2016 (173\% increase) and that of male deaths increased from 18 in 1990 to 32 in 2016 (78\% increase) (Table 1).

Most deaths occurred at the age of $\geq 55$ years for both the sexes. A total of 568 deaths ( 345 men and 223 women) occurred among patients with TC aged $20-54$ years, and 1,762 deaths (510 men and 1,252 women) occurred among those aged $\geq 55$ years. The peak age at which deaths occurred in men was 70-74 years, which was lower than that in women (75-79 years) (Figure 1). The crude and standardized mortality rates in this Ecuadorian population and those in the world population are presented in Table 1.

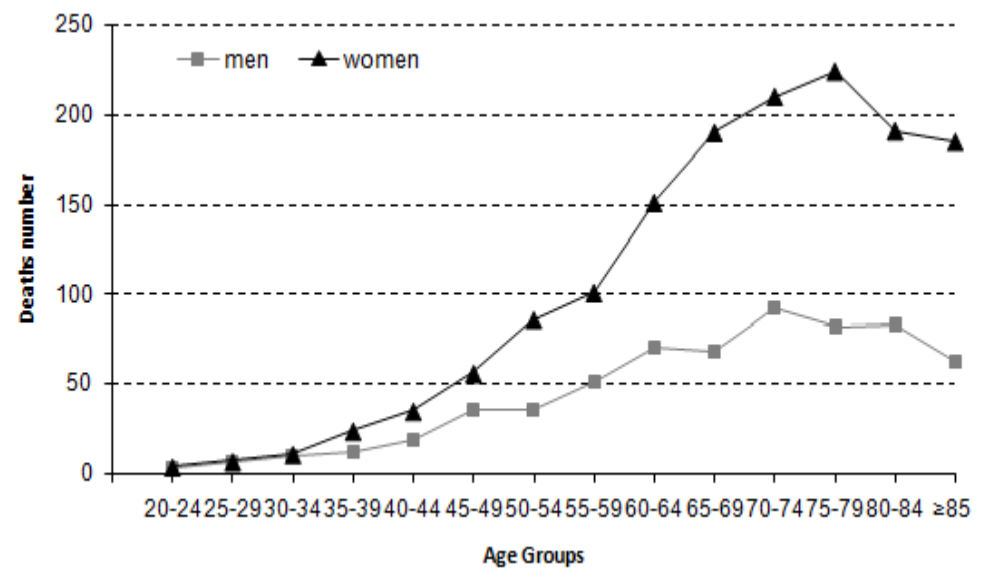

Figure 1: Mortality due to thyroid cancer according to age and sex from 1990 to 2016

Table 1: Number of deaths and crude and age-standardized mortality rates (direct method, world standard population) per 100,000 women and men (all ages) due to thyroid cancer in Ecuador

\begin{tabular}{|c|c|c|c|c|c|c|}
\hline \multirow{3}{*}{ Year } & \multicolumn{3}{|c|}{ Women } & \multicolumn{3}{|c|}{ Men } \\
\hline & \multirow{2}{*}{ Number of deaths } & $\begin{array}{l}\text { Ecuadorian } \\
\text { population }\end{array}$ & $\begin{array}{c}\text { World Standard } \\
\text { Population }\end{array}$ & \multirow{2}{*}{ Number of deaths } & $\begin{array}{l}\text { Ecuadorian } \\
\text { population }\end{array}$ & $\begin{array}{c}\text { World Standard } \\
\text { Population }\end{array}$ \\
\hline & & Crude rates & $\begin{array}{c}\text { Age-standardized } \\
\text { rates }\end{array}$ & & Crude rates & $\begin{array}{c}\text { Age-standardized } \\
\text { rates }\end{array}$ \\
\hline 1990 & 37 & 1.05 & 1.32 & 18 & 0.69 & 1.08 \\
\hline 1995 & 34 & 0.86 & 1.02 & 17 & 0.56 & 0.84 \\
\hline 2000 & 37 & 0.82 & 0.91 & 14 & 0.41 & 0.55 \\
\hline 2005 & 60 & 1.19 & 1.23 & 25 & 0.64 & 0.85 \\
\hline 2010 & 28 & 0.62 & 0.72 & 68 & 1.55 & 0.85 \\
\hline 2015 & 100 & 1.98 & 2.08 & 30 & 0.61 & 0.72 \\
\hline 2016 & 101 & 1.96 & 2.02 & 32 & 0.64 & 0.73 \\
\hline
\end{tabular}


The mortality rate in men showed a statistically nonsignificant decrease during the study period, with an estimated APC of $-0.4 \%(95 \% \mathrm{CI}$ from -2.4 to $1.5 ; \mathrm{P}=0.70)$ and an AAPC of $-0.4 \%(95 \% \mathrm{CI}$ from -2.4 to $1.5 ; \mathrm{P}=0.70 ; \mathrm{P}=0.70$ ) without any identified jointpoint.

The mortality rate in women showed a significant decrease between 1990 and 1998 with the estimated APC being $-6.6 \%$ (95\% CI from -12.5 to $-0.3 ; \mathrm{P}<0.05)$. However, it showed a significant increase between 1998 and 2016 with the APC being $5.4 \%(95 \%$ CI from 3.4 to $7.3 ; \mathrm{P}<0.05)$, and at an identified jointpoint, the AAPC was $1.4 \%(95 \% \mathrm{CI}$ from -1 to $3.7 ; \mathrm{P}=0.30)$ (Figure 2).

There were more deaths due to TC in the Andean region (69\%) than in the coastal region (29\%), the Amazon region (2.3\%), or the Galapagos Islands (0.2\%). The mostly densely populated provinces, Pichincha and Guayas, showed the highest number of deaths. The Andean provinces with the highest number of deaths were Pichincha $(n=574)$, Tungurahua $(n=162)$, Azuay $(n=162)$, and Chimborazo ( $\mathrm{n}=120$ ) (Figure 3).

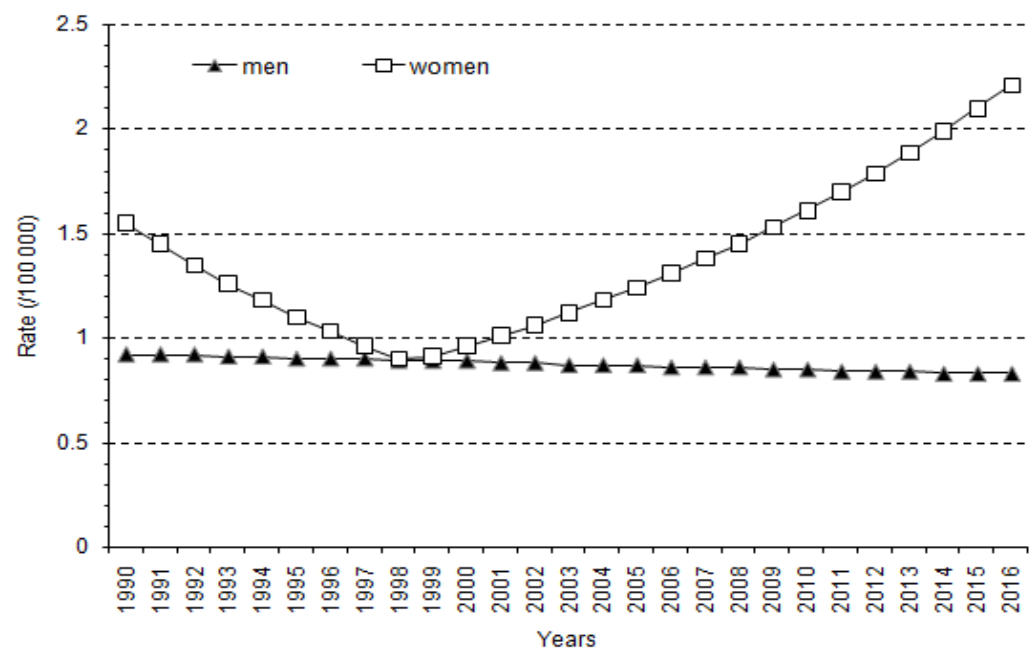

Figure 2: Trends in thyroid cancer mortality in Ecuador between 1990 and 2016, as assessed using a jointpoint regression model for men (triangle) and women (squares) The World Health Organization world standard population was used for standardizing the age ranges, and the age-standardized rate was calculated per 100,000 person-years

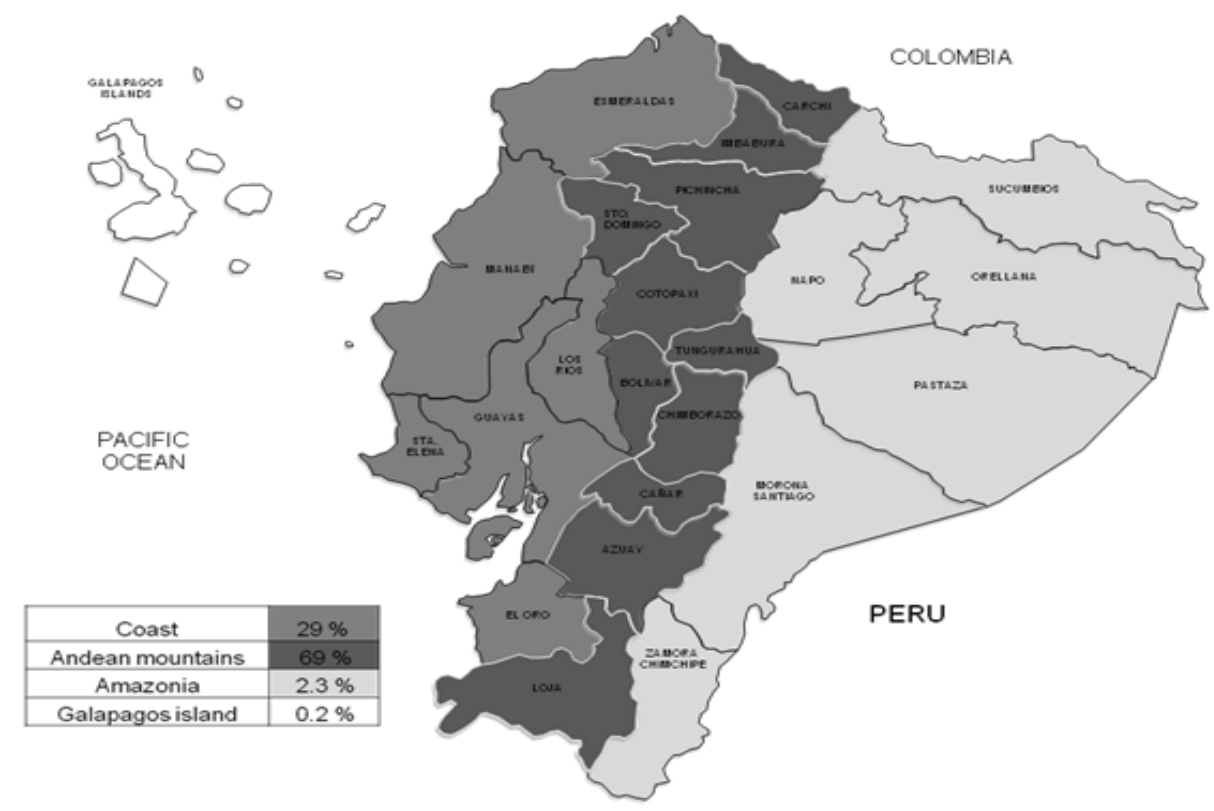

Figure 3: Mortality due to thyroid cancer in different geographical regions of Ecuador from 1990 to 2016 
The mortality rate projection per 100,000 women is predicted to increase from 2.36 in 2020 to 4.56 in 2050 , whereas that per 100,000 men is predicted to increase from 0.92 in 2020 to 1.09 in 2050 (Table 2).

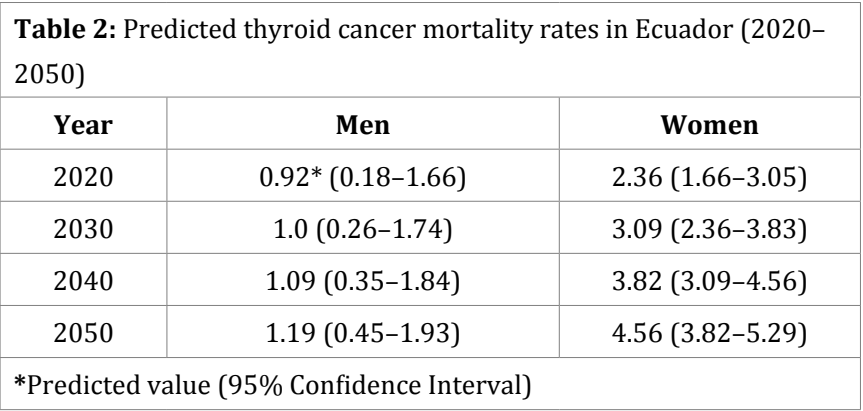

\section{Discussion}

To the best of our knowledge, the present review is the only population study on temporal trends in TC mortality in Ecuador to date. This study included numerous events $(2,107$ deaths), covered a long duration (26 years), and involved the entire Ecuadorian population.

Previous studies show that Ecuadorians have high TC incidence and mortality rates [7] [12, 13]. Our findings indicate a persistent increase in TC mortality in women (between 1997 and 2016) and a moderate decrease in TC mortality in men (from 1990 to 2016). It is noteworthy that these findings diverge from the reported global trends $[7,13]$.

Epidemiological studies show that the TC incidence has continuously increased in the United States, Canada, Australia, Europe, Asia, and the Middle East and continues to increase in most countries worldwide [6,7]. Nevertheless, this has not been accompanied by a concomitant increase in male or female mortality, which has in fact decreased, as reported by studies in Europe and the United States [14-17].

In 2012, the worldwide TC mortality rates corresponded to approximately 0.6 per 100,000 women and 0.3 per 100,000 men [7]. According to the GLOBOCAN 2012 database, the average standardized mortality rate is 1.1 per 100,000 individuals in Ecuador (1.4 women and 0.7 men) [12].

An analysis of worldwide TC mortality rates shows steadily decreasing trends for both the sexes, albeit with some notable exceptions. For men, the mortality rate has decreased in all major countries, with an APC of approximately $-2 \%$ and $-3 \%$ from 1970 to 2012 [7].

In the United States, TC mortality declined until the mid '80s, after which it eventually increased [18]. TC mortality in women declined from 1990 to 2012 in most countries, with an APC of approximately $-2 \%$ and $-5 \%$, apart from the United Kingdom, United States, and Australia, countries in which mortality decreases until the end of the 80 s and 90 s and either stabilized or increased thereafter [7].

More recently, the overall average TC mortality slightly increased by $0.8 \%$ between 1992 and 2013 (0.4\% in women and
$1.5 \%$ in men) according to the Surveillance, Epidemiology, and End Results (SEER) program (1975-2013) [19].

From 2008 to 2012, most countries showed mortality rates (standardized by age and world population) between 0.20 and 0.60 per 100,000 women and between 0.20 and 0.40 per 100,000 men. The countries with the higher mortality rates in men $>0.4$ per 100,000) were Latvia, Hungary, Moldova, and Israel, whereas those with higher mortality rates in women $(>0.6$ per 100,000$)$ were Ecuador, Colombia, and Israel [7].

Several Latin American countries, including Ecuador, Brazil, Costa Rica, and Colombia, show higher TC incidence rates for both sexes in comparison to developed countries such as the United States and Canada [13, 20]. Although the TC mortality rates in these countries are relatively low for both sexes $(<1.0)$, those in Ecuador, Mexico, Colombia, Panama, and Peru are among the highest in the world [13], are three times higher than those in women in the United States (0.3) observed from 2003 to 2007, and are comparable to those found in Hungary, Israel, and Estonia (all with a rate of 0.5 ) for the same period [21].

The variations observed in TC mortality rates according to sex in Ecuador may reflect the fact that the increased TC incidence is higher in women than in men [22] and, therefore, could represent, at least partially, a high proportion of over diagnosis in women. However, this is expected to result in a decline in the mortality rates [23] and not in their growth as observed in our analysis.

The use of ultrasound and fine needle aspiration for diagnosing TC may contribute to its early detection but not necessarily to its timely treatment. Patients may be diagnosed at an advanced stage of the disease, or they may carry a more aggressive type of TC, thus influencing the increase in mortality.

Because TC incidence showed a sharp increase in the early 1990 s, a noticeable increase in the death rate should have been perceived after 10-20 years. According to Howlader et al., this is exactly what is occurring: the trend in TC mortality as observed by the SEER program from 2001 to 2010 indicates a total AAPC of $0.9 \%(0.9 \%$ in women and $1.6 \%$ in men $)$ [24]. In fact, the reported increase in TC mortality over the past 10 years is not only statistically significant but is also more rapid than that of other types of cancer, apart from hepatic cancer [25].

Consequently, TC mortality would continue to increase in relation to the increase in high incidence, albeit with a delay, which would be justified by the low aggressiveness of TC [26]. In the present study, we noted that the increasing mortality rate in women follows a pattern resembling that reported in the United States, Australia, and the United Kingdom, with a decrease observed till the end of the '90s, followed by stabilization or subsequent increase [7].

Unequal distribution in TC incidence and the related mortality across different regions of a given country have been reported [27, 28]. Residency in areas with endemic goiter is a risk factor for TC, and TC mortality is associated with residing in mountainous areas, which may be a reflection of iodine deficiency [8]. For instance, TC mortality in Spain is high for people living in geographical areas associated with iodine deficiency, which 
are mainly in the northwestern part of the country and in the Pyrenees [27].

TC mortality tends to be high in regions with endemic goiter because tumors frequently develop during advanced stages, as detected at the time of diagnosis, and also due to the presence of a high proportion of aggressive TC subtypes [27, 29]. A higher frequency of deaths observed in the Ecuadorian regions with endemic goiter [mountainous) in the present study is therefore consistent with previously published findings. Iodine intake may influence the occurrence of a specific histological subtype of TC, with follicular TC being most frequently found in iodine-deficient areas and papillary CT in areas with high iodine intake [22, 2931].

High TC incidence rates are observed in Ecuador, Brazil, Costa Rica, and Colombia, and high TC mortality is observed in Ecuador, Colombia, Mexico, Panama, and Peru, all of which have a history of iodine deficiency and goiter [13, 32, 33]. Ecuador was jointly declared as iodine-deficiency free by the ICCIDD, PAHO, and UNICEF only in 1999 [34].

Our findings may be explained by the fact that in the areas with endemic goiter-socially traditional, mountainous regions with poor sanitation and low development-TC may not be diagnosed in time [27]. In Ecuador, the rural Andean region has been historically considered as endemic with goiter. Therefore, our results indicate a high risk of death due to TC in such provinces.

Furthermore, the possible existence of a genetic predisposition in the host or a tumor that influences TC mortality, as described in other ethnicities [35] should not be ruled out. Along this line, the relative isolation of the afflicted areas (which were practically inaccessible until a few years ago) may be characterized by a tendency toward high consanguinity. The hypothetical presence of aggressive histological subtypes of TC in such areas as well as the possible influence of other unknown genetic or environmental factors could be considered as etiological hypotheses [27].

Although some previous reports imply that the prognosis of TC mortality in men is poorly understood, contrary findings have also been reported $[6,35,36]$. Our findings differ from the widely held belief that men show poorer outcomes than women when diagnosed with TC $[6,35]$. Nevertheless, the underlying reason for mortality being higher in women than in men as observed in our study is unclear.

Owing to the design of the present study, it is only possible to speculate on the potential reasons behind the observed trend in TC mortality. We were unable to determine a specific cause underlying the increased TC mortality rate observed in women.

Our study has certain limitations. First, the mortality data extracted from death certificates do not provide detailed information on the histological subtypes of TC. With no histological information, the influence of the disease stage on mortality could not be established, which could account for up to one-third of the observed increase in mortality rates [18].

Second, because we extracted data from death certificates, we were unable to include other potentially confounding factors with respect to mortality, such as age at diagnosis, treatment type, socioeconomic status, occupational exposure, and other environmental aspects.

Despite these limitations, our study is highly relevant and is supported by the completeness (70\%-90\%) [37] of records on the vital statistics of Ecuador, the long duration of the datacollection period, the national scope of the registry of deaths, and the use of AAPC as an average measure of the temporal trend.

\section{Conclusion}

TC mortality in Ecuador tended to decrease in men and women from 1990 to 1998. Although this trend persisted for men, TC mortality in women increased from 1998 to 2016. The TC mortality rate is predicted to increase for both sexes in the coming decades. The precise reason for the observed increase in TC mortality in Ecuadorian women from 1998 onwards remains unclear.

Overall, TC mortality in Ecuador is low; however, Ecuador ranks among the top 10 countries with the highest TC mortality rates in the world. Mortality rates also reflect, to some extent, the incidence of a disease in a specific population. Indeed, Ecuador is ranked among the top 10 countries with the highest TC incidence rates in the world. A high proportion of advanced-staged tumors during diagnosis can also impact mortality rates.

Delays in diagnosis and treatment due to limited access to healthcare in remote or rural areas, poor infrastructural access to care centers, and other genetic or environmental factors could attribute to the increase in TC mortality in Ecuadorian women.

Further studies are required to investigate the factors influencing changes in TC mortality in Ecuador.

\section{References}

1. Carling T, Udelsman R. Thyroid cancer. Annual Review of Medicine. 2014;65:125-137. Doi: 10.1146/annurev-med-061512-105739

2. Forman D, Bray F, Brewster DH, GombeMbalawa C, Kohler B, Piñeros $M$, et al. Cancer Incidence in Five Continents Volume IX. IARC Scientific Publications No. 164. International Agency for Research on Cancer Lyon, France. 2014.

3. Husson O, Haak HR, van Steenbergen LN, Nieuwlaat WA, van Dijk BAC, Nieuwenhuijzen GA, et al. Rising incidence, no change in survival and decreasing mortality from thyroid cancer in The Netherlands since 1989. Endocrine-related Cancer 2013;20:263-271. Doi: 10.1530/ ERC-12-0336

4. Davies L, Welch HG. Current thyroid cancer trends in the United States. JAMA Otolaryngology-Head \& Neck Surgery 2014;140(4):317-322. Doi: 10.1001/jamaoto.2014.1

5. Cordioli MI, Canalli MH, Coral MH. Increase incidence of thyroid cancer in Florianopolis, Brazil: comparative study of diagnosed cases in 2000 and 2005. Arquivos Brasileiros de Endocrinologia \& Metabologia. 2009;53(4):453-460. Doi: 10.1590/S0004-27302009000400011

6. Guimarães RM, Muzi CD, Parreira VG, Santos RD \& Sampaio JR. Evolution of thyroid cancer mortality in adults in Brazil. Arquivos Brasileiros de Endocrinologia \& Metabologia. 2013;57(7):538-544. Doi: 10.1590/S0004-27302013000700007 
7. La Vecchia C, Malvezzi M, Bosetti C, Garavello W, Bertuccio P, Levi F, et al. Thyroid cancer mortality and incidence: a global overview. International Journal of Cancer 2015;136(9):2187-2195. Doi: 10.1002/ijc.29251

8. Minelli G, Conti S, Manno V, Olivieri A, Ascoli V. The geographical pattern of thyroid cancer mortality between 1980 and 2009 in Italy. Thyroid 2013;23(12):1609-1618. Doi: 10.1089/thy.2013.0088

9. Población y Demografía. Defunciones Generales y Fetales-Bases de Datos. 2017.

10. Estimaciones y proyecciones de población total, urbana y rural, y económicamente activa. CELADE - División de Población de la CEPAL. Revisión 2017.

11. Jointpoint Regression Program, Statistical Methodology and Applications Branch, Surveillance Research Program, National Cancer Institute. Version 4.5.0.1. 2017.

12. GLOBOCAN 2012 (IARC) Section of Cancer Surveillance.

13. Sierra MS, Soerjomataram I, Forman D. Thyroid cancer burden in Central and South America. Cancer Epidemiology 2016;44:S150S157. Doi: 10.1016/j.canep.2016.07.017

14. Dal Maso L, Lise M, Zambon P, Falcini F, Crocetti E, Serraino D, et al; AIRTUM Working Group. Incidence of thyroid cancer in Italy, 19912005: time trends and age-period-cohort effects. Annals of Oncology. 2011;22(4):957-963. Doi: 10.1093/annonc/mdq467

15. Sipos JA, Mazzaferri EL. Thyroid cancer epidemiology and prognostic variables. Clinical Oncology 2010;22(6):395-404. Doi: 10.1016/j. clon.2010.05.004

16. Netea-Maier RT, Aben KK, Casparie MK, den Heijer M, Grefte JM, Slootweg $\mathrm{P}$ et al. Trends in incidence and mortality of thyroid carcinoma in The Netherlands between 1989 and 2003: correlation with thyroid fine-needle aspiration cytology and thyroid surgery. International Journal of Cancer 2008;123:1681-1684. Doi: 10.1002/ ijc. 23678

17. Lin JD, Chao TC, Sun JH, Ho C, Weng HF. Trends in the clinical characteristics of patients with papillary thyroid carcinoma in Taiwan. Oncology 2000;58:280-285.

18. Lim H, Devesa SS, Sosa JA, Check D, Kitahara CM. Trends in thyroid cancer incidence and mortality in the United States, 1974-2013. JAMA 2017;317(13):1338-1348. Doi: 10.1001/jama.2017.2719

19. National Cancer Institute. Trends in SEER Incidence and US Mortality. 2018

20. Cancer Incidence in Five Continents, Vol. X, International Agency for Research on Cancer, 2014.

21. Mortality Database, World Health Organization. 2014.

22. Pellegriti G, Frasca F, Regalbuto C, Squatrito S, Vigneri R. Worldwide increasing incidence of thyroid cancer: update on epidemiology and risk factors. Journal of Cancer Epidemiology 2013;2013:965212. Doi: $10.1155 / 2013 / 965212$

23. Ho AS, Davies L, Nixon IJ, Palmer FL, Wang LY, Patel SG, et al. Increasing diagnosis of subclinical thyroid cancers leads to spurious improvements in survival rates. Cancer 2015;121(11):1793-1799. Doi: 10.1002/cncr.29289
24. Howlader N, Noone AM, Krapcho M, Garshell J, Neyman N, Altekruse SF, et al. SEER Cancer Statistics Review, 1975-2010, National Cancer Institute. 2013.

25. Rahib L, Smith BD, Aizenberg R, Rosenzweig AB, Fleshman JM, Matrisian LM. Projecting cancer incidence and deaths to 2030: the unexpected burden of thyroid, liver, and pancreas cancers in the United States. Cancer Research 2014; 74(11):2913-2921. Doi: 10.1158/0008-5472.CAN-14-0155

26. Vigneri R, Malandrino P, Vigneri P. The changing epidemiology of thyroid cancer: why is incidence increasing? Current Opinion in Oncology 2015;27(1):1-7. Doi: 10.1097/CCO.0000000000000148

27. Lope V, Pollán M, Pérez-Gómez B, Aragonés N, Ramis R, Gómez-Barroso D, et al. Municipal mortality due to thyroid cancer in Spain. BMC Public Health. 2006;6:302. Doi:10.1186/1471-2458-6-302

28. Mitchell I, Livingston EH, Chang AY, Holt S, Snyder WH, Lingvay I, et al. Trends in thyroid cancer demographics and surgical therapy in the United States. Surgery 2007;142(6):823-828. Doi: 10.1016/j. surg.2007.09.011

29. Zimmermann MB, Galetti V. Iodine intake as a risk factor for thyroid cancer: a comprehensive review of animal and human studies. Thyroid Research 2015;8:8. Doi: 10.1186/s13044-015-0020-8

30. Blomberg M, Feldt-Rasmussen U, Andersen KK, Kjaer SK. Thyroid cancer in Denmark 1943-2008, before and after iodine supplementation. International Journal of Cancer 2012;131:23602366. Doi: $10.1002 / \mathrm{ijc} .27497$

31. Harach HR, Galíndez M, Campero M, Ceballos GA. Undifferentiated (anaplastic) thyroid carcinoma and iodine intake in Salta, Argentina. Endocrine Pathology 2013;24(3):125-131.

32. Fierro-Benítez R, Penafiel W, De Groot LJ, Ramirez I. Endemic goiter and endemic cretinism in the Andean region. New England Journal of Medicine. 1969;280(6):296-302. Doi: 10.1056/ NEJM196902062800604

33. Pretell EA, Delange F, Hostalek U, Corigliano S, Barreda L, Higa AM, et al. Iodine nutrition improves in Latin America. Thyroid 2004;14:590599. Doi: 10.1089/1050725041692909

34. Ministerio de Salud Pública. Ecuador celebra el Día Nacional del Yodo cumpliendo estándares internacionales. 2018.

35. Nguyen MT, Hu J, Hastings KG, Daza EJ, Cullen MR, Orloff LA et al. Thyroid cancer mortality is higher in Filipinos in the United States: An analysis using national mortality records from 2003 through 2012. Cancer. 2017;123(24):4860-4867. Doi: 10.1002/cncr.30958

36. Bukvic B, Sipetic S, Kalezic N, Diklic A, Paunovic I, Kovacevic B, et al. Changing trends in mortality of thyroid cancer in Belgrade population. J BUON. 2011;16(2):337-340.

37. WHO methods and data sources for country-level causes of death 2000-2015.C2. 2017. 